\title{
Tal vez contaré mi historia. Una lectura de La Vie Scélérate de Maryse Condé1
}

\author{
Laura LÓPEZ MORALES \\ Universidad Nacional Autónoma de México
}

\begin{abstract}
En su novela La Vie Scélérate, Maryse Condé, nacida en la isla de la Guadalupe, traza dos líneas históricas paralelas: una que recorre la trayectoria de cuatro generaciones de una familia y, la otra, inscrita en la primera, relacionada con la historia oficial en la que destacan algunas de sus páginas más significativas. Sobresale la manera como la autora entreteje los principales ejes temáticos desarrollados en otras de sus obras: los conflictos identitarios, la discriminación racial, el papel de la mujer...
\end{abstract}

PALABRAS CLAVE: identidad, historia, negro, blanco, cultura, raza.

In the novel La Vie Scélérate, Maryse Condé, born in Guadeloupe Island, draws two parallel story lines: one tells the story of four generations of a family, and the other, in which the first one is inscribed, belongs to the official History. The most significant pages of the novel are encompassed in this second part. The way in which the author brings back the main themes developed in some of her previous works is: identity conflicts, racial discrimination and the role of women...

KEY WORDS: identity, story, black, white, culture, race.

La novela de Maryse Condé nos introduce, sin complacencias ni disfraces, en el imaginario antillano a través del relato que recoge los avatares, sueños y aventuras de varias generaciones de una familia de la isla Guadalupe. La saga de los Louis va entretejiéndose con la historia del siglo XIX y sobre todo del XX.

Como en círculos concéntricos, tres de los personajes de esta familia se proponen reconstruir su filiación: Coco, la narradora, última generación de la dinastía, ${ }^{2}$ se da a la tarea de desenterrar y ensamblar las piezas de la historia familiar. Jean, hermano menor de Jacob, idealista con madera de rebelde y redentor, sueña con escribir la historia de la isla para enseñar a su pueblo a asumir y a enorgullecerse de su verdadera identidad

\footnotetext{
${ }^{1}$ Seghers, París, 1987. A esta edición corresponderán las citas incluidas en este trabajo y de las que ya sólo se incluirá la página. La traducción de las mismas es nuestra.

${ }^{2}$ Se anexa al final el cuadro genealógico que permitirá ubicar mejor a cada personaje.
} 
cultural. Por último, Thécla, la sobrina de Jean, madre de la narradora, después de muchas andanzas por Europa y América, de diversas experiencias que la confrontan a sus fantasmas personales y a los de su pueblo, decide acometer la historia de los "movimientos revolucionarios del mundo negro".

Mientras vemos a los personajes de cuatro generaciones desenvolverse en diferentes contextos, sin sustraerse al devenir de la historia, la novelista no se priva de hacer, a manera de telón de fondo, un sinnúmero de alusiones a las obsesiones y fantasmas del imaginario antillano:

- la búsqueda de las raíces,

— el color de la piel vivido como estigma, pero también la reivindicación de los orígenes,

- el odio por el blanco, pero también el complejo de lactificación, ${ }^{3}$

— el conflicto entre una realidad desmitificada y la aspiración a una vida lúcida y dignificada.

La evocación o alusión a hitos importantes de la historia oficial permite pues contextualizar algunos de los episodios personales de los diferentes miembros de la dinastía Louis. La referencia a determinados hechos históricos se convierte en una suerte de pauta que expresa el propio devenir de la familia, con sus necesarios cambios y sus no menos inevitables lastres. Porque, salvo ciertos pasajes en los que algunos de los personajes se consideran - efímeramente - satisfechos con lo que son y tienen, el universo descrito por Maryse Condé en esta novela parece no ofrecer muchas salidas: veremos cómo hombres y mujeres, en diferentes momentos de la historia, protagonizan situaciones recurrentes en las que son víctimas de una tradición que los estigmatiza, dando pie a tres tipos de comportamiento: por un lado, la aceptación lúcida y orgullosa de su identidad (que conduce al odio por el blanco y a la exaltación de los orígenes no europeos); por otro, la conducta mimética que sobre-estima los valores del blanco, europeo o americano, y, por ende, la descalificación de cualquier rasgo asociado a la identidad de todo pueblo colonizado y, por si fuera poco, negro. Y finalmente, la voluntad de integrar y conciliar los diversos rasgos raciales y culturales que la historia ha impreso a su paso.

\section{Las historias en la historia}

Sigamos ahora el curso de las generaciones en relación con algunos hechos históricos reales: los padres del primer Albert Louis, con cuya historia se abre el relato, respiran todavía la atmósfera de la esclavitud recién abolida en 1848. No es de extrañar entonces que esa experiencia marque de manera tan profunda el carácter de su descendencia. El propio Albert decide, a los treinta y dos años, ir a trabajar a Panamá en las obras

\footnotetext{
${ }^{3}$ Véase Frantz Fanon, Peau noire, masques blancs. París, Seuil, 1952.
} 
del canal que se inician en 1904: “Grandes eran las tentaciones para la mayoría de los trabajadores importados para estos planes [que] provenían de islas como Jamaica, Barbados, Santa Lucía, Martinica y Cuba. Este gran éxodo [...] reflejaba el caudal de la compañía francesa de Ferdinand de Lesseps que después de haber construido el canal de Suez había firmado entonces un contrato con Colombia para construir el Canal de Panamá" (Lewis, 1988: 81).

Por diferentes razones, Lesseps abandona sus planes y Estados Unidos retoma el proyecto que dura de 1904 a 1914. Es así como Albert encuentra allí a otros negros antillanos que, como él, no entienden bien a bien ¡que haya igualmente negros norteamericanos! El viejo Seewall, un jamaiquino avecindado en Panamá desde hacía muchos años, ríe de la ignorancia de sus congéneres: “¡Montón de ignorantes! ¡Vaya si son tontos! Los mismos barcos que se detuvieron en nuestras islas para vender a nuestros antepasados continuaron hasta Norteamérica donde otros blancos compraron a los de éstos!" (32).

Se trata de un descubrimiento importante cuando la historia de un individuo y de un pueblo han sido cortadas del resto del mundo. Pero el problema no está tanto en su ignorancia de la historia oficial como en comprender que esos negros estadounidenses, a pesar de sus raíces comunes, en su calidad de capataces se comportan como los blancos: “¿Nuestros hermanos? ¿Nuestros hermanos? Ya viste la ametralladora que cargan esos negros ¡Ésos no son hermanos!” (idem.). ¿Cómo era posible tal cosa, si los Estados Unidos era el país de la libertad, si el americano era blanco? Años después, cuando Jacob, segundo hijo de Albert, pretende lanzarse a la política se convierte en la mira de sus propios compatriotas; Albert intenta persuadirlo: “!No lo hagas! ¡No lo hagas! Nos odian. No nos perdonan haber dejado los cañaverales. Quisieran vernos sobre una carreta de bueyes con el látigo en la mano. Te bañarán con mierda como hicieron conmigo [...] Lo único que tienen negro es la piel. Son peores que los blancos" (129). Con todo, el descubrimiento adquiere una importancia doble porque en la experiencia de la miseria y la explotación, Albert también llega a ver emerger la solidaridad que hermana a los pobres de cualquier raza. Durante los años pasados en Panamá, Albert cobra conciencia del destino común de los desheredados y es entonces cuando escucha por primera vez el nombre del famoso líder sindical jamaiquino, Marcus Garvey (18871940), cuyo lema "I shall teach the Black man to see beauty in himself" refuerza su odio y desprecio por los blancos. El ideal jamaiquino se convierte en una obsesión. La aparición de Garvey en el contexto de las obras del canal, por las condiciones en que viven los peones, adquiere un valor simbólico en la conciencia de Albert.

Ya de regreso a la Guadalupe, tres años después y antes del inicio de la Primera Guerra Mundial, Albert se deja picar por el gusanito que el viejo Seewall, padre de su adorada Liza, muerta al nacer el pequeño Albert, le había contagiado en Panamá: la leyenda de los gambusinos que se volvían ricos en el oeste de Estados Unidos. La obsesión por salir de pobre y el espejismo de conocer "'América!"4 bastan para lanzar-

\footnotetext{
${ }^{4}$ Entiéndase: Estados Unidos de Norteamérica.
} 
se a una aventura que le reserva sorpresas más bien desagradables. En San Francisco conoce al chino Chi-Lu-Lee, cuya experiencia como inmigrado ofrece muchos puntos en común con el destino marginal y explotado de los negros.

\begin{abstract}
Mi padre, mi abuelo y, antes que él, el padre de mi abuelo hicieron crecer los tallos de arroz en la provincia de Kwang-Tung, de la que Cantón es la capital. Siempre con la espalda encorvada, las palmas de las manos llenas de callos y la vida mutilada de las esperanzas que tuvo al nacer. Yo también empecé como ellos en el infierno verde de los arrozales. Y un buen día, me harté. Levanté la cabeza hacia el sol y le dije: “¿Qué no brillas también para mí? Entonces dame fuerzas. Ya no quiero una vida así". Pedí dinero prestado y tomé el barco hacia Kum Shan.... (San Francisco) [...] Cuando haya juntado un buen fajo de billetes verdes, regresaré a mi casa (51).
\end{abstract}

En San Francisco, Albert pierde a su amigo Jacob que conoció en Panamá y en cuya memoria bautiza con su nombre al primer hijo que tiene con Elaïse. Por responder a los insultos de un blanco en un bar, el negro Jacob, siempre obediente a la prudencia que su madre le había inculcado frente a los blancos, amaneció acribillado y destrozado en el fango. Albert se repuso con dificultad de ese golpe. En el viaje de San Francisco a Pointe-à-Pitre empieza a escribir un diario que su bisnieta recupera y en el que descubre algunos rasgos reveladores de su antepasado: "Una inteligencia por encima de la normal, pero que por desgracia ninguna lectura había enriquecido. Una sensibilidad en carne viva. Una susceptibilidad autodidacta. Ninguna guía. Ningún modelo, aparte de Marcus Garvey, visto de lejos. En resumen, ese diario es una secuencia de interrogantes que harían sonreír a un hombre instruido" (56).

Como vemos, la que lleva el hilo del relato de principio a fin es la bisnieta, quien escudriña en los pliegues de la memoria familiar los datos faltantes, las páginas inconclusas, los silencios envenenados, sin descuidar su propia inserción en el flujo de la historia oficial. Así que retomaremos el hilo cuando Albert regresa a la Guadalupe llevando consigo al hijo de Liza, su primera esposa. Con el dinero ahorrado se dedica al comercio e inicia así una vida de prosperidad económica. Se casa en segundas nupcias con Elaïse formando así el tronco del que saldrán las diversas ramas de la dinastía que culmina con la narradora. Albert, hosco y hermético, se concentra en labrarse una posición respetable: compra una serie de viviendas miserables con las que lucra aprovechando la desgracia de los más pobres. Este modus vivendi frente a sus ideales de reivindicación de sus hermanos de raza se traduce en una grave paradoja, en una terrible incongruencia, que pronto se ve obligado a reconocer. La noticia del "Congreso de los pueblos negros de la tierra", a celebrarse en París en 1920, despierta en él la necesidad de ayudar a la causa de la dignidad de la raza negra: “él, que había observado una reserva a la vez orgullosa y prudente, escribió a los políticos que debían asistir a ese Congreso para asegurarles su apoyo a tan exaltante misión de rehabilitación de la raza desposeída y para ofrecerles humildemente acompañarlos, pese a su escasa instrucción" (77); ante tal gesto de generosidad la prensa de la isla no desperdicia la oportunidad de denunciar 
su impostura: “¿A quién pretenden engañar? Un explotador no tiene color. No es ni negro ni blanco ni mulato. Los guadalupeños, que desde que salieron de la noche de la esclavitud han dado tantas veces prueba de su madurez política, no se dejarán engañar con estas mascaradas. Al buen entendedor pocas palabras!” (77). Albert se convirtió en el blanco de las crueles mofas del pueblo y su reacción fue la de encerrarse en un mutismo lleno de rencor y amargura.

Siguiendo el hilo cronológico de la historia oficial no falta por supuesto la evocación de la atmósfera de efervescencia protagonizada por antillanos y africanos en el París de la entre-guerra, con el surgimiento del movimiento de la Negritud. El arte negro - música, pintura, literatura - es portador de una ideología que persigue el rescate y valoración de la raza negra y de sus tradiciones culturales. No obstante, tal parece que los ideales encabezados por figuras de primer orden, como el martiniqueño Aimé Césaire, el senegalés Léopold Sédar Senghor y el guyanés Léon Gontran Damas, y aplaudidos por la elite intelectual y artística europea, no permearon en la conciencia de la masa, pues en la vida cotidiana los negros siguieron siendo (y me atrevería a decir que siguen siéndolo en muchas latitudes) individuos de segunda clase, condenados a la discriminación y al desprecio del blanco. Es así como Bert, el hijo de Albert nacido en Panamá, se hunde en la autodestrucción después de haber tratado de abrirse paso como músico en París. Después de un breve paréntesis de calma y de esperanza que vive gracias a la relación con una obrera francesa, su existencia se cierra con una muerte trágica que nunca se supo si fue suicidio o accidente. De la unión con la rubia Marie nace Bebert, padre de Aurelia, que, por cierto, los azares del destino ponen en el camino de la narradora, su prima, y le revela esta parte ignorada de la historia familiar.

Pero regresemos a esos años treintas. En vísperas de la Segunda Guerra Mundial, cuando corren los primeros rumores acerca de la inminencia del conflicto bélico, en la isla se respira una atmósfera de temor ante la eventualidad de afrontar penurias en caso de que la madre patria fuera ocupada por los alemanes. Los consejeros generales de la isla empiezan a pensar en medidas precautorias y, dada la reputación de Jacob en el medio de los negocios, lo invitan a formar parte de la misión económica que iría a negociar a Nueva York algunos contratos. El hijo de Albert tenía entonces veinticuatro años y nunca había salido de la isla, así que la invitación fue recibida como un verdadero honor. El viaje de Jacob tuvo un doble valor: al anunciar a su padre la noticia, éste salió de su mutismo habitual y pidió lo siguiente:

- ¿Vas a Nueva York? Entonces, le entregarás a Marcus Garvey una carta de mi parte. Allá tiene una oficina. ¡Sabes quién es Marcus Garvey?!

Jacob, que nunca había oído ese nombre, guardó silencio y su padre exclamó con la misma rapidez:

— ¡El negro más grande de todos los tiempos! ¡No hay tres, ni dos como él! (119). 


\section{$232 \square$ TAL VEZ CONTARÉ MI HISTORIA}

Para darnos una idea de lo que la figura del líder jamaiquino representaba a los ojos de Albert, vale la pena conocer los términos en los que este hombre parco y seco le dirigió la misiva:

Mi muy querido Marcus Garvey,

Ya no podré verlo con mis propios ojos. Pero mi hijo le entregará esta carta y podrá aprovechar sus exaltantes enseñanzas, más de lo que yo fui capaz. No he hecho nada con mi vida. Y sin embargo, con usted me siento orgulloso de mi raza. Creo en una raza negra pura. Por ello me he sentido herido hasta el corazón. Ahora vivo como un salvaje, enmudecí, ensordecí. Me convertí en el Mundongo, en el Subaru ${ }^{5}$ del que ella [Liza] se reía. No obstante sigo creyendo que nuestra raza se vengará de todas las humillaciones que no ha dejado de sufrir día tras día. Sé que la historia que construiremos asombrará al mundo (119).

Por su parte, Jacob descubre que la diáspora negra representa millones de hermanos diseminados por doquier y que en todas partes son víctimas de la inferiorización. Lo peor de todo - $-\mathrm{y}$, como ya dijimos, eso constituye uno de los puntos cruciales de la identidad antillana: por un lado, renegar de su raza y aspirar al modelo cultural del blanco y, por el otro, reivindicar sus raíces sin aceptar las irreversibles marcas de la herencia cultural europea que dejó la colonización-, es que muchas veces son los propios negros los que se encargan de denigrar, de descalificar y despreciar los esfuerzos de algunos idealistas que como Jean, hermano de Jacob, se empeñan en rescatar la memoria ancestral para que el pueblo asuma, preserve su identidad auténtica y se sienta orgulloso de ella.

Hasta aquí los trozos recuperados se han centrado en dos de los personajes del clan Louis, pero, como en todas las familias, cada miembro toma un rumbo diferente a pesar de salir del mismo contexto. Brillante en los estudios, Jean, último hijo de Albert, decide, sin embargo, convertirse en maestro rural en vez de seguir una carrera universitaria pues está convencido de que eso lo transformará en una detestable copia de los explotadores de su pueblo y de sus cómplices. Así que en cuanto puede se instala en el pueblo de Grands-Fonds-les-Mangles. Empieza por ganarse a los campesinos hasta entonces desconfiados con los maestros; consigue que le ayuden a construir una escuela improvisada y el primer día de clase se presenta a los alumnos con estas palabras: "-Es preciso que sepan que yo no sé nada. ¡Así que vengo a aprender todo aquello que ustedes han recibido de quienes les dan de beber y de comer! Son ellos los que saben..." (132).

Extrañados, los niños creen primero que se trata de una broma, pero no tardan en convencerse de que el maestro dice la verdad y poco a poco empiezan a confiarle todo lo que saben:

\footnotetext{
${ }^{5}$ Mundongo, raza de esclavos conocidos por su carácter taciturno; Subarú, salvaje.
} 
Primero cosas materiales. Cómo se hace aceite y jabón de coco. Cómo se puede construir una cabaña fresca e impermeable con varas. Cómo la liana esponja suaviza la piel. Cómo el aceite de ricino desenreda el cabello, pero también alumbra sin humear. Cómo el vetiver trenza los canastos. Y luego, ¡esas cosas secretas, apenas articuladas, que transmiten sobre todo las mujeres, madres, abuelas, bisa y tatarabuelas! ¡Curar, sanar o también atacar las enfermedades! ¡Incluso mortales! (133).

Con toda esa información Jean llenó cuadernos y cuadernos. Pero sus fuentes ya no se limitaron a lo que le contaban los niños; pronto éstos lo introdujeron en sus propias familias y allí descubrió sus usos, costumbres y tradiciones en todos los aspectos de la vida. A su regreso a casa consignaba en sus libretas cuanto había visto convencido de que eso constituía la verdadera cultura de su pueblo y de que era necesario preservar a toda costa ese saber. Esto representó el giro más decisivo en la vida de Jean pues de aquí brotó el germen de su proyecto de escribir la verdadera historia de la isla. Las lecciones que recitaban los alumnos de Jean reflejaban esas convicciones: "En otro tiempo, mi tierra, mi isla, la Guadalupe, se llamaba Karukéra. Aquí vivían hombres que no sabían matar ni hacer daño. Se alimentaban con peces que sacaban del mar y de los ríos de hermosas aguas. Cultivaban el tabaco, la yuca y el maíz" (139). Hay que precisar que esto era una verdadera audacia, en épocas en que a los nativos no les enseñaban la historia de la Guadalupe; semejante temeridad no tardaría en costarle caro.

Tras siete años y medio de trabajo, en 1953, año de la muerte de Stalin, Jean publica La Guadalupe desconocida, que la prensa local acoge con comentarios burlones ante la ingenuidad de su autor que todavía se atrevía a hablar de lo sobrenatural como parte del imaginario popular. Por desgracia la cosa no para en eso, pues poco después Jean recibe la visita de un inspector que reprueba sus enseñanzas y a paso seguido envía un reporte que le vale la expulsión del cuerpo docente. Jean se retira definitivamente a una aldea y se niega a recibir ayuda de su hermano Jacob, doce años mayor que él y a quien considera un burgués contaminado por los ideales de los blancos.

Es también durante esos años cincuentas, y no es de extrañar dada la atmósfera independentista que entonces se respira en las ex colonias, cuando se registran algunos brotes revolucionarios en la isla.

\section{La historia desde la mirada femenina}

Para la década siguiente quien ocupa el primer plano de la historia es Thécla, hija única de Jacob y de Tima, y madre de la narradora. El caso de este personaje es uno de los que mejor encarna la problemática y el conflicto cultural del antillano.

Los padres de Thécla la rodearon de toda clase de mimos y apoyos para tener una vida privilegiada. De hecho esta hija permitía a Tima afianzar su posición frente a Jacob y a su familia que se había percatado del arribismo de la nueva. La belleza y la astucia 
de esta muchacha de extracción modesta embrujaron al joven y tímido potentado, y con el nacimiento de Thécla, Tima se convirtió en el verdadero eje del clan: "Desde el día siguiente de la boda, Elaïse [segunda esposa de Albert y madre de Jacob] delegó en Tima la dirección del hogar y jésta se convirtió en la única, en la verdadera Sra. Louis! Con excepción de Elaïse, a quien trataba como a una madre, Tima hizo que la casa marchara al paso. La sirvienta aprendió a bajar los ojos y a no replicar. Los hermanos de Jacob a tender sus camas y a vaciar sus bacinicas. Los parientes y amigos a no visitar más que con invitación" (106).

Sin embargo, sin dejar de reconocer la belleza y el carácter de Tima, la narradora señala con toda objetividad que su abuela escapaba a la imagen tradicional de la mujer antillana, trabajadora, solidaria con su pareja en la lucha por el sustento de la familia y, en ocasiones, única responsable de la manutención del hogar. "Hay algo que me impresiona cuando pienso en mi abuela, muerta sin que yo la conociera: es que no trabajaba. A diferencia de Elaïse que cuando sonaban las ocho ya debía estar en la escuela, golpeando su escritorio con la regla para callar a los alumnos escandalosos o para despertar a los dormidos antes de recitar: 'Nuestros antepasados galos'” (197).

Aquí conviene precisar un detalle relativo al perfil que la literatura antillana nos ofrece de las mujeres. Casi por regla general los personajes femeninos, creados por hombres o mujeres, responden al estereotipo de la víctima resignada, abnegada, o de la que, como en el caso de Simone Schwarz-Bart en Pluie et vent sur Télumée Miracle, no se doblega ante la desgracia, más bien lucha contra la adversidad y mantiene la frente en alto. Algunas de estas mujeres buscan una escapatoria a su enajenación cuando se dan cuenta de que la realidad no les ofrece ninguna, optan por la única retirada posible como es la tentación de la muerte o de la locura. En todo caso, los personajes femeninos rara vez encajan en el perfil de mujeres felices e improductivas.

A este respecto, Elizabeth Wilson nos dice que "una de las características comunes más evidentes en las obras de las escritoras antillanas que, por cierto, han gustado de contar la historia de antepasados o hermanos de raza, es el punto de vista autobiográfico, intimista, rasgo que encontramos también en la escritura femenina africana, anglófona" (Wilson, 1987: 19). En el caso de Maryse Condé, el esquema propuesto por E. Wilson debe ser matizado, pero en esencia sigue siendo válido por lo que toca a la reconstrucción histórica: "La estructura narrativa refleja el estado de ánimo y la coyuntura en que se encuentra la narradora/protagonista. El relato autobiográfico en primera persona conviene particularmente bien al viaje introspectivo de la mujer. Se cuentan varias historias en flashback" (ibid.: 21-22). Sobre la mayoría de la producción femenina antillana, la narrativa de Simone Schwarz-Bart destaca por romper con la imagen de la mujer víctima, resignada y doblegada por su doble destino marginal: ser negra y mujer. Con Pluie et vent sur Télumée Miracle esta novelista, por cierto paisana de Maryse Condé, ofrece otra imagen de la mujer, la que decide pelear contra el destino y sobreponerse a todas las influencias negativas del entorno. Schwarz-Bart recurre también al modelo de la saga familiar, sólo que en su caso las figuras dominantes son mujeres: las Lougandor. De Minerve a Télumée, estas mujeres luchan por "llevar las riendas de su caballo", 
mantenerse a flote sobre las olas que las golpean y nunca bajar la frente. La propia Maryse Condé opina al respecto:

Resulta obvio que es preciso cuidarse de interrogar demasiado a la literatura y considerarla como el equivalente del discurso etnológico o político. En el acto de escribir existen demasiados elementos que hacen de él una aventura individual. Sin embargo, a través de ella, es posible circunscribir la imagen de una colectividad e incluso de vivir un momento con ella. Si la novela representa el mundo íntimo que un escritor entreabre, es también un testimonio social [...] El discurso [de las escritoras de las Antillas] no resulta optimista ni triunfalista. Está cargado de angustias, de frustraciones y de rechazos. Pero eso no es exclusivo de las Antillas. A través del mundo, la palabra de las mujeres rara vez es triunfante. [...] No obstante, dado el contexto particular de las Antillas, angustias, frustraciones, rechazos se enuncian de manera diferente (Condé, 1993: 126).

Este paréntesis sobre alguno de los rasgos característicos de la literatura y de la imagen de la mujer en las letras antillanas nos permite captar mejor la trayectoria de Thécla y el origen de sus conflictos internos. Como apuntamos anteriormente, la hija de Jacob y de Tima nació durante la Segunda Guerra Mundial que despertó los ánimos "patriotas" de algunos colonizados. René, el hermano menor de Jacob, decide alistarse en las filas de la Resistencia encabezada por el general De Gaulle. Por cierto que, así como René parece estar en defensa de la Madre Patria, Brother Ben, un negro estadounidense que Jacob conoce en Nueva York, le externa la misma idea: "!Cuando se trata de defender a los Estados Unidos, entonces sí nuestra sangre es lo suficientemente roja! El resto del tiempo, nos matan en todas las calles" (126).

Al margen de estos vaivenes históricos, Thécla crece en medio de los mimos más extravagantes y acostumbrada a toda clase de caprichos, de modo que estaba muy lejos de imaginar los conflictos identitarios vividos por otros miembros de su familia y que tiempo después enfrentaría ella misma:

[Jacob] le compraba a precio de oro manzanas francesas o uvas moscatel y la chiquilla ignoraba que los plátanos y los mangos crecían en los árboles para saciar el hambre de los pequeños desheredados de su edad. Tima, en su miedo por perderla, la vistió sólo de blanco hasta los doce años y la calzó con lustrosos botines, en sus vestidos de organza, adornados con encajes, [era] llevada de la mano por una sirvienta que sostenía una sombrilla y la mochila, hasta la escuela privada de las Señoritas Virtuosas (137).

Los niños no dejaban de darse cuenta de que Thécla era grosera y despótica con la servidumbre y, en el fondo, de despertar en ellos una cierta envidia, compartida como dijimos por otros antillanos, por esa supuesta promoción social que se traducía en la imitación del modelo cultural de los blancos: "Los domingos, [Thécla] acompañaba a Tima a la misa mayor, con la caballera torturada desde la víspera a fuerza de alaciado y llena de moños, amontonados bajo su sombrerito en tela inglesa" (138). Las preten- 
siones de Tima acabaron por crear en torno a su hija un clima totalmente artificial, falso y hostil que la convertirían en un ser todavía más inadaptado. Víctimas del complejo que Franz Fanon llamaría lactificación, muchos antillanos sucumben a la tentación de adoptar gustos, costumbres y modales que, supuestamente, los igualan a los blancos.

Con estos antecedentes, Thécla padece las consecuencias de una visión distorsionada de la realidad, sobre todo cuando al insertarse en la sociedad metropolitana confronta los postulados ideológicos de la Europa de los años sesentas con lo que había respirado en su entorno familiar, a un tiempo pretendidamente burgués y orgulloso de sus raíces negras. "Sus padres le habían hecho creer que había nacido para ser una reina. Cuando se dio cuenta de que para la mayoría de la gente distaba mucho de ser la verdad, no pudo reponerse y, de repente, quiso revolucionar todo" (282-283).

El testimonio autobiográfico de la propia Maryse Condé abunda en este sentido:

Yo fui educada por unos padres que decían todo el tiempo: "Hay que sentirse orgullosos de ser negros". Hay gente que tiene el problema contrario, que dicen que justamente sus padres presentaron y vivieron el hecho de ser negros como una tara. Así que a lo largo de su infancia y hasta la edad adulta son desdichados, están en desventaja... En mi caso es exactamente al revés. Me repetían cuán hermoso es ser negro. Nuestra familia era la más inteligente, la más sobresaliente. Llegué a detestar a todos los que me rodeaban. Al mismo tiempo, no veía nada en nuestra vida cotidiana que valorizara el hecho de ser negros. Lo único que veía entre los míos era una imitación absoluta del modo de vida occidental, una admiración de sus valores, en una palabra, una total asimilación. Es una ambigüedad la que me tocó vivir y que muy pronto quise resolver yendo al encuentro de negros de verdad, con derecho a decir: "Sintámonos orgullosos de ser negros", porque su vida, su modo de vida, su cultura son acordes con su discurso, su vivencia con sus palabras (Condé, 1993: 125-126).

En su lucha interna, la adorada hija de Jacob da el primer traspiés de una serie que convertiría su vida en una cadena de intentos malogrados por realizar sus aspiraciones, aun sin saber bien a bien en qué consistían y consciente del daño que iba causando a su paso. Al terminar sus estudios en la Sorbona, queda preñada por un blanco y Thécla confía a su propia hija, la narradora de toda la historia, la huella que le deja este embarazo no deseado:

Es verdad, eres la hija de mi vergüenza y de mi pena. Es algo que no puedo olvidar. Cuando estás frente a mí, no eres tú, chiquita, a quien estoy viendo. Es a tu padre con su sonrisa blanca y hermosa de muchacho bien educado cuando en realidad el último de los cortadores de caña era mucho más honesto que él. Y es también a su madre a la que veo, con todas sus ínfulas preguntando de qué familia salía yo y olfatear con cara de asco el olor a bacalao salado de nuestro nombre. Pues nadie habló nunca de mi color que, en el fondo, era el verdadero problema. No se habla del color, aunque esté allí saltando a la vista: jeso no se hace! ¡El color es más sucio que la diarrea verde de la disentería amibiásica o los orines amarillos azufre de la incontinencia! ¡Sí, cuando te veo, no es mi culpa, 
es todo eso lo que veo! ¡Estupidez crasa, arrogancia limitada, mezquinería, oh, mezquinería! (ibid.: 274-275).

La relación de Thécla con un blanco fue una afrenta como lo fueron la de Jean con Marietta, que era una blanca pobre, pero blanca; la de Bert con Marie, y, años después, la de Dieudonné, hijo mayor de Jean. Éste, con el tiempo y pese a sus convicciones, acaba de mandar a sus hijos a estudiar a Francia; Dieudonné termina la carrera de derecho en Clermont-Ferrand y a su regreso a la Guadalupe se percata de que la imagen de su padre en la isla corresponde a la de un mártir. ¿Accidente o suicidio? ¡Vaya usted a saber! Jean se ahoga en una crecida del río, pero el retiro en que pasó el resto de su vida, el exilio voluntario, defendiendo con idealismo y sinceridad, pero con soberbia, sus convicciones, lo rodearon de una aureola heroica, así que sus funerales resultaron una manifestación multitudinaria de gente que lo admiraba sin entenderlo bien, cómo alguien que todavía podía morir por "la independencia".

Serge, su otro hermano, quien mientras René moría en Francia en las filas de De Gaulle, cerraba los ojos ante los representantes del gobierno de ocupación en la isla y escalaba en los peldaños de la sociedad asimilada, se presenta al sepelio luciendo en el ojal la insignia de la Legión de Honor. Sin embargo, la pena por la muerte de Jean era sincera y se arrepentía de haberlo tratado de demagogo e impostor y reconocía que para llevar una vida como la de Jean en defensa de sus convicciones se requería mucho valor e integridad.

Así, la generación siguiente, la de Thécla y Dieudonné, marcaría otro giro en la lucha por entender y asumir una identidad, como dice la narradora, comparable a la de un "mango injertado". Al reinstalarse en la isla, el primogénito de Jean, que había adoptado los gustos y modales de la metrópoli — se estremecía con Proust y vibraba con Bach-, no tarda en medir el peso que representa afirmarse en la sociedad guadalupeña bajo la sombra santificada de su padre. De manera inexplicable para muchos, la metamorfosis se produce y, de pronto, Dieudonné se pone a defender a los campesinos explotados y vejados. En sus litigios empieza a asumir la causa de los desheredados y a apoyar sus iniciativas encaminadas a la creación de cooperativas que les permitan una vida más digna con el fruto de su propio trabajo. No pasa mucho tiempo antes de que el joven abogado transforme su simpatía por las causas populares en militancia política declarada. Decide fundar un partido político cuyo programa se esforzaría por superar, sin traicionar ni claudicar, los radicalismos de unos y otros. El tío Jacob se alarma e intenta convencerlo de renunciar a su proyecto recordándole todas las penas vividas en la familia: Albert, Jean y él mismo, a causa de la política. Pero Dieudonné no ceja y, con tono condescendiente pero firme, trata de explicar a su tío por qué su posición ya no es la misma que la del resto de la familia: "En tu tiempo, ustedes dividían al país en tres. Los blancos, que les daban miedo, sí, miedo. Los mulatos, ja los que envidiaban, sí, sí, envidiaban! Y ustedes, los negros, que detrás de los bellos discursos de deber hacia la raza, se odiaban unos a otros. No es con semejantes ideas con lo que ustedes hubieran hecho avanzar al país... Yo soy tan guadalupeño como ustedes! Dieudonné 
era partidario de una independencia más abierta, menos sectaria, con rostro humano" (ibid.: 288-289).

Un punto más en el que Dieudonné y Thécla confirman su pertenencia a la misma generación, la de aquellos que se formaron en Francia y que sin renegar de sus orígenes ni comulgar totalmente con la política asimilacioncita, asumen, no sin dificultades, el destino de toda sociedad mestiza. Dieudonné sacude una vez más las estructuras familiares al casarse con Monique, una rubia francesa. "Adiviné, nos dice la narradora, que de nuevo mi familia iba a incorporarse sangre de otro color" (290). Un miembro más de la familia que, a los ojos de los orgullosos de la pureza de la raza, había roto esa especie de pacto de sangre.

\section{Entre ficción y realidad}

Nuestro planteamiento inicial apuntaba a la estrecha relación estructural entre el hilo de las historias individuales y la pauta marcada por algunos hechos importantes de la historia oficial de Occidente en la que los personajes participan aunque sea anónimamente. Sin embargo, conviene subrayar una relación más esencial entre los dos planos cronológicos. De diferentes maneras y acaso por distintas razones, la mayoría de los integrantes de la familia de los Louis siente la necesidad de conocer su identidad, individual y colectiva. Esta búsqueda conduce casi ineluctablemente a la toma de conciencia de la dimensión política que entraña toda reivindicación del derecho de cada individuo o grupo a ser plenamente lo que son y ser respetados como tales. Así hay que entender la idealización de Albert en torno a la figura de Marcus Garvey, los frustrados intentos de Jacob, la campaña de reconstrucción y de rescate de la cultura de su isla emprendida por Jean, los proyectos más intelectuales de Thécla de escribir la "historia de los movimientos revolucionarios del mundo negro" y, en fin, hasta el sacrificio de René en la Resistencia francesa, como para convencerse de su auténtica pertenencia a la madre patria en peligro.

En muchos casos, la lucha por la afirmación de la identidad conduce a los personajes (y nos atreveríamos a ver en ellos la posición de sus autores) a la reivindicación de la libertad y de la independencia políticas. El anticolonialismo asume diferentes rostros desde la rebeldía de los cimarrones y los levantamientos de esclavos siglos atrás, hasta el credo filosófico de la Negritud y, más recientemente, la bandera de la Antillanidad y de la Creolidad; las manifestaciones han ido cambiando en función de las circunstancias y de las diferentes formas de dominación política, económica y cultural, pero el denominador común de todas ellas es la defensa de la identidad.

Toda generalización es abusiva, por lo que consideramos necesario matizar las afirmaciones anteriores, sobre todo en lo que se refiere a los movimientos identitarios de la última mitad del siglo XX. En otro momento señalamos el conflicto de que es víctima el antillano entre la aspiración al modelo del blanco y la necesidad de afirmarse como negro. Aunque nuestras apreciaciones se apoyan en ejemplos sacados de la literatura, 
nos atrevemos a tomarlos como reveladores de la realidad; de suerte que dada la diversidad de vivencias y de experiencias de un individuo a otro, de un grupo a otro, el abanico de posiciones al respecto es muy amplio.

Para Jacques Chevrier, junto al conservadurismo, junto a una cierta prudencia o, incluso, a una cierta desilusión resultado del fracaso de las utopías nacionalistas africanas de los años sesentas, las expectativas libertarias de algunos antillanos se atenuaron dejando paso a la creencia de que la "preservación y [la] afirmación de la identidad y de la personalidad cultural antillana era posible en el marco francés" (Chevrier, 1989: 10); de hecho, los defensores de la Antillanidad y de la Creolidad, herederos de la Negritud, comparten parcialmente esta posición pues al no querer privilegiar ninguna de sus raíces culturales por encima de las demás: "ni europeos, ni africanos, ni americanos, ni asiáticos" (Bernabé et al., 1990: 9), dan por sentada su filiación con todas.

No obstante estoy consciente de que el problema es más complejo y de que por sí solo amerita un desarrollo más amplio y mejor sustentado. Si ahora lo evoco es para contrastar esta actitud con el abierto anticolonialismo que asumen otros antillanos y, de nuevo, visto a través de la literatura. Citaré una vez más a Chevrier, quien subraya las críticas abiertas de Maryse Condé a la "clase política corrupta" de su tierra. "Una vez pasada la exaltación del primer contacto con la madre África, los antillanos, ávidos de recuperar sus raíces y de colmar el vacío histórico con ese encuentro, no pueden menos que constatar el abismo cultural, psicológico, político y social que los separa de sus parientes africanos: la poligamia, el Islam, la organización social diferente... son algunos de los espacios en los que los contrastes dificultan la adaptación de unos a otros" (ibid.: 10). Los africanos rechazan en ocasiones a esos mestizos contaminados por la cultura occidental y éstos deben rendirse ante la evidencia de que cuatro siglos de colonización y de contacto con los europeos los han marcado tan hondo, para bien y para mal, que difícilmente su actual visión del mundo puede identificarse ciento por ciento con la de los africanos, ajenos a la experiencia de la esclavitud, pero también menos expuestos e influidos por el modelo cultural europeo.

En varios de sus textos de los años sesentas y setentas, Maryse Condé adopta posiciones abiertamente militantes pero no menos lúcidas; las experiencias decepcionantes que consigna en Heremakhonon y en Une Saison à Rihata, resultado de su estancia en África, no la conducen a una idealización, por reacción, de su tierra natal. Sin abandonar su postura anticolonialista, juzga con severidad a sus compatriotas, a quienes reprocha sus "cobardías, arribismo, falta de solidaridad, vacío de ideología, apetito de confort, en resumen, [su] inmovilismo" (idem).

La reflexión y la postura de Maryse Condé no se manifiestan únicamente en el discurso literario. Por su formación universitaria, la novelista también orienta su búsqueda hacia los terrenos de la sociología y de la antropología como prueban otros textos igualmente militantes: La Civilisation du bossale, La Parole des femmes. Pero ni las desilusiones ni el escepticismo han menguado su convicción política como dice Chevrier: "Su negritud no es narcisista, y no adquiere sentido sino inserta en el combate colonialista" (Chevrier, 1989: 11). 
A medida que el relato va acercándose a su término, después de haber registrado las mil vicisitudes familiares, el tono desencantado de la mayoría de los sobrevivientes del clan nos deja un sabor pesimista. El balance de la lucha libertaria librada por cada uno, en aras de ideales comunes o de causas diferentes, parece ser descorazonador. En una de las escenas finales en que la narradora resume los últimos capítulos de la historia familiar, recuerda que esas vacaciones fueron especialmente tórridas: hombres, animales y naturaleza jadeaban y se crispaban por la sequía. El calor era tal que "una vieja llamada Esperanza pereció carbonizada bajo el techo de lámina de su choza” (331).

Nos preguntamos si ése es el horizonte condenado que la autora percibe para su pueblo. Sin embargo, después de esta escena, no deja de abrirnos un pequeño resquicio en las últimas páginas tratando de superar cualquier sectarismo. En una plática entre la narradora y Gesner, un eterno enamorado de Thécla, éste le dice:

Mira esta tierra, la nuestra, la tuya, subastada. Tal vez dentro de poco sólo sea un recuerdo que poco a poco adelgazaré en las memorias. Lo que yo trato de decir es que hay que conservarle su voz. Y tú también puedes, tú debes hacer algo. Todavía no lo sabes y yo no puedo guiarte, yo que no fui a las escuelas que fueron ustedes. La obra de tu tío abuelo Jean no ha terminado [...] tú eres la criatura de nuestro mañana. ¡Piénsalo! [... La narradora] no veía qué responderle, rebelándose y asustándose en secreto ante la promesa que quería arrancarle, de ese papel que quería endilgarle, de esa misión que quería encargarle (333).

A pesar de su resistencia, ella acepta que algo más fuerte que su propia voluntad orientará y dará sentido a su existencia: “¿acaso podría yo hacer que la sangre de todo mi linaje mintiera?" (idem). En el fondo, sentía la necesidad de responder a Gesner la amenaza inminente de "ese tiempo en que ya nadie sabría contar el pasado familiar por conocerlo. En que los vivos ya no vendrían al mundo al cabo de interminables gestaciones de vientre en vientre para dotarse de un capital genético secular. En que el presente ya no sería más que el presente. ¡Y el individuo, sólo el individuo!” (330).

Al final de cuentas, creemos que la autora, al igual que la narradora, están decididas a vivir su propia historia sin sustraerse al devenir de la historia colectiva y oficial y en la que se inscribe la de su pueblo, ya que ninguna historia se escribe sobre una tabula rasa. Sin sucumbir a falsas utopías ni a la descalificación de un pasado y un presente portadores de sombras pero también de luz, la vida y la obra de Maryse Condé representa ese valor testimonial que garantiza el necesario puente entre el ayer, el hoy y el mañana. 
LAURA LÓPEZ MORALES $\square 241$

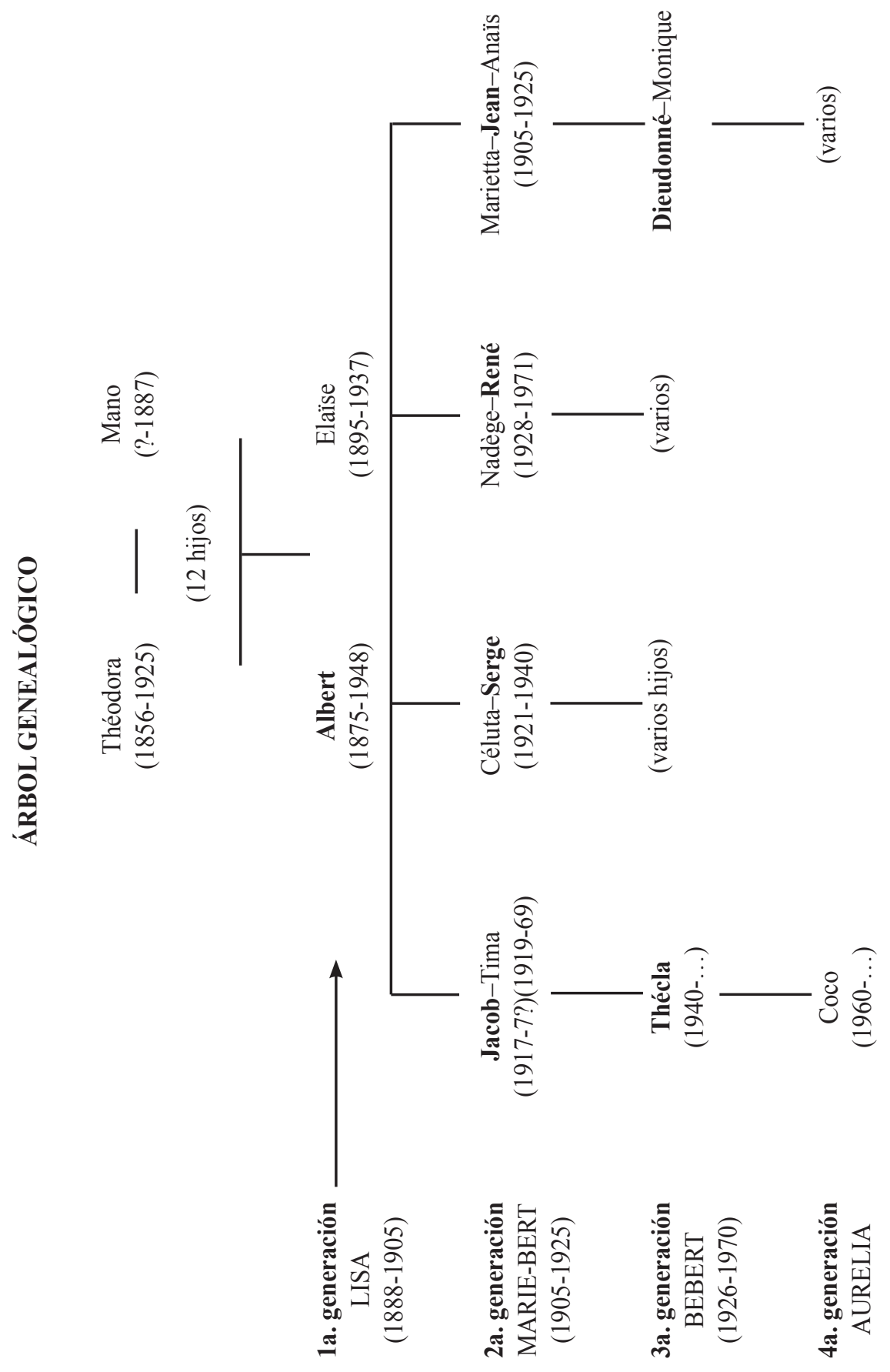




\section{Obras citadas}

BERNABÉ, Jean et al. 1990. Éloge de la Créolité. París: Gallimard.

CONDÉ, Maryse. 1993. La Parole des femmes. París: L'Harmattan. 1987. La Vie Scélérate. París: Seghers.

CHEVRIER, Jacques. 1989. "Voix féminines en Martinique et en Guadeloupe". Primer Coloquio de Literaturas Francófonas. México.

LewIS, Rupert. 1988. Marcus Garvey, paladin anticolonialista. La Habana: Casa de las Américas. (Nuestros Países)

WILSON, Elizabeth. 1987. "Regards sur l'écriture féminine des Antilles Françaises". Chemins Actuels, núm. 36. Pp. 16-20. 